\title{
Meckel's Diverticulum - Rare Complications and Review of the Literature
}

\author{
Sqn Ldr D R Andrew \\ FRCS (Glasg), RAF* \\ Consultant General Surgeon \\ Miss K M Williamson \\ MRCOG
}

Senior Registrar in Obstetrics and Gynaecology

Department of General Surgery, Glenfield General Hospital, Leicester

SUMMARY: Meckel's diverticulum is the most common congenital anomaly of the gastro-intestinal tract. It arisesio as a result of incomplete dissolution of the vitello-intestinal duct. Approximately 4\% of patients with Meckel'so diverticula develop complications, most commonly obstruction, gastro-intestinal bleeding and inflammation. We describe three unusual presentations of Meckel's diverticulum - perforation due to ingested foreign body, a $\overrightarrow{0}$ smooth muscle neoplasm simulating an ovarian tumour, and a Littre's hernia.

\section{Introduction}

Medical students are taught the "Rule of Two" (1) for Meckel's diverticula: the diverticulum is two inches in length, lies two feet from the ileo-caecal valve, is present in two per cent of the population, has a male:female predominance of $2: 1$, and may contain two types of ectopic mucosa (gastric or pancreatic). Meckel's diverticula are commonly encountered as incidental findings at laparotomy, but some $4 \%$ produce complications, the most frequent being gastro-intestinal bleeding inflammation and small bowel obstruction (2). We describe three patients we treated who had rare complications of Meckel's diverticula.

\section{Case 1}

A 35-year old male engineer was admitted with a 24hour history of lower abdominal pain, maximal in the right iliac fossa. He denied any gastro-intestinal or urinary symptoms. Examination revealed a mild pyrexia and a moderate tachycardia. There was tenderness across the lower abdomen, with guarding and rebound tenderness in the right iliac fossa. Bowel sounds were normal. Haematological testing showed a leucocytosis of 13,900 per cu $\mathrm{mm}$.

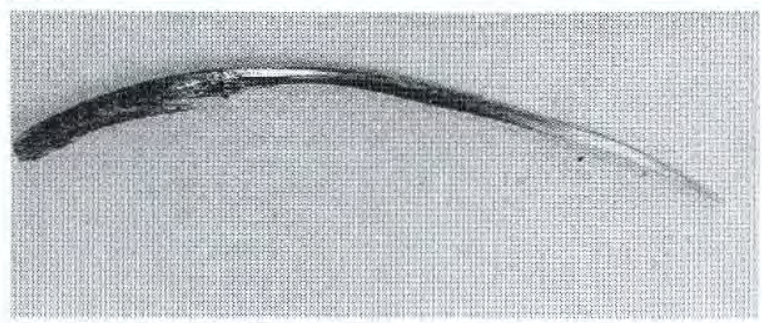

Fig 1. Fish bone which perforated a Meckel's diverticulum.

A diagnosis of acute appendicitis was made but at operation the appendix was normal. A Meckel's diverticulum four centimetres long was found with a three centimetre long "thorn" (Fig 1) protruding through the wall . A second "thorn" penetrated the terminal ileum. The diverticu- lum was resected and the ileal perforation was oversewn The patient made an uneventful recovery.

Histological examination showed acute inflammator changes in the diverticulum. The "thorns" were sent to the Natural History Museum in London for identification Chemical analysis showed them to contain calciume apatite, most probably of fish bone origin.

\section{Case 2}

A 58-year old post-menopausal woman was referred gynaecological opinion of a pelvic mass. She gave a tg year history of lower abdominal discomfort. On exami tion a mass arising from the pelvis was palpable in fo right iliac fossa. On vaginal examination the uterus bulky and retroverted and the mass was readily palpag in the right adnexa.

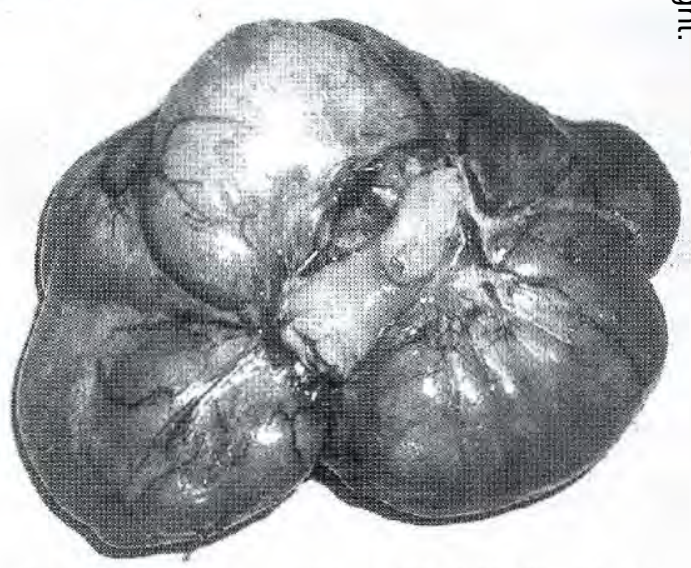

Fig 2. Spindle cell tumour arising in Meckel's diverticulum.

Examination of the urine was unremarkable. The ovar ian tumour marked $\mathrm{Ca}-125$ Antigen was in the normat range. Ultrasonography revealed a mass at the righ? adnexa measuring $78 \times 80 \times 93$ millimetres, with a mixecus echo pattern and areas of calcification. The left ovarỹ appeared normal, but no ovary could be identified on the्ल 
right. This suggested that the mass was a tumour of the right ovary. At operation however, both ovaries were found to be normal, but a large mass in a Meckel's diverticulum was excised (Fig 2).

The pathology report confirmed a small bowel diverticulum $25 \mathrm{~mm}$ in length with a solid mass arising from the wall. Histology showed that this was a spindle cell tumour, originating from smooth muscle. Immohistochemistry was positive for smooth muscle antibody.

\section{Case 3}

A 95-year old lady presented with a two day history of colicky central abdominal pain, abdominal distension and profuse vomiting. On examination the abdomen was distended, with visible peristalsis, and active, high-pitched bowel sounds. No scars were apparent, and palpation elicited only minor generalised tenderness, with no guarding and no masses. In the right femoral triangle was a four centimetre diameter non-pulsatile swelling which was moderately tender; no cough impulse could be elicited.

The blood count showed a leucocytosis of 15,800 per $\mathrm{cu} \mathrm{mm}$. Blood urea and electrolytes and serum amylase were normal. Abdominal radiographs confirmed dilated small bowel loops suggestive of obstruction.

The diagnosis of small bowel obstruction secondary to a strangulated femoral hernia was made. A laparotomy revealed an obstructing femoral hernia containing an ischaemic Meckel's diverticulum. The strangulated segment was resected and the hernia repaired, and the patient made a rapid and uneventful recovery.

\section{Discussion}

In 1700, the French surgeon Alexis Littre (1658-1725) reported two cases of a small bowel diverticulum lying in a femoral hernia sac. He thought that the outpouchings of the bowel were acquired from the juxtaposition of the bowel and the femoral canal. Johann Friedrich Meckel (3) (1781-1833) described diverticula of the distal ileum in 1812 and suggested that the diverticulum might have a congenital origin. Meckel's diverticulum is a true diverticulum in that it consists of all intestinal layers. It is the most common congenital anomaly of the gastro-intestinal tract (4) and arises from incomplete obliteration of the vitello-intestinal duct. The duct usually disappears at the fifth to ninth week of intra-uterine life, but its dissolution may be incomplete, giving rise to a variety of anomalies (Table 1).

\section{Table 1 \\ Anomalies resulting from incomplete obliteration of the vitello-intestinal duct}
Meckel's diverticulum
entero-umbilical fistula
unbilical sinus
persistent fibrous cord
mesodiverticular vascular band
omphalomesenteric duct cyst
strawberry umbilical tumour

Meckel suggested that the diverticulum might have complication rate as high as $25 \%$, but recent publications (5) suggest that $4 \%$ is a more accurate figure (Table 2$) \underset{\Phi}{\overparen{D}}$ Because of the risk of complications, Ludtke et al (6) rec 2 ommended prophylactic resection of Meckel's diverticuls even if asymptomatic, unless there were contra-indica tions. This policy is supported by other authors $(7,8)$, but? Leijonmarck et al (9) calculated that the risk of complica $\overrightarrow{\bar{F}}$ tions in adult patients is only $0.03 \%$ and diverticulectom was associated with a $6 \%$ rate of complications. They rec $\frac{\sigma}{0}$ ommended that symptomless diverticula should not be्क resected. Mackey and Dineen (10) and Pickard and Simp $\widetilde{\Phi}$ son (11) agreed that diverticulectomy in the absence of complications or risk factors was not justified. Factors ${ }^{\infty}$ associated with a higher risk of complications includẹ male sex, age below forty, a diverticulum more than twi centimetres in length or with a narrow neck, the presence् of heterotopic mucosa, or the existence of a diverticula band.

\section{Table 2}

Complications associated with Meckel's diverticulum

haemorrhage

obstruction

diverticulitis

umbilico-enteric fistula

perforation

intussusception

foreign bodies

neoplasia - benign or malignant

peptic ulceration

Littre's hernia

\section{Comment}

Case 1. Performation of a Meckel's diverticulum is :ैّ rare occurrence. The first case was reported in 1899 bẙ Blanc (12). In 1982, McDowell and Bush (1) reviewe forty cases of perforation of Meckel's diverticulum in the world literature and found that most cases had simulatec acute appendicitis and that $65 \%$ were due to fish-bones.

Case 2. In a review of 2507 cases of gastro-intestinaB. smooth muscle tumour Skandalakis and Gray (13 reported that $28 \%$ were in the small bowel, with $0.8 \%$ (21) arising in Meckel's diverticula. Of these, 6 were⿸户 benign tumours and 15 malignant. The distinctior between benign and malignant smooth muscle tumours can be difficult to determine, and their subsequent behav 3 . iour hard to predict (14). Prognosis is related to the preva. lence of mitoses, cellular atypia, the presence of necrosis and tumour size (15).

Case 3. Although Littre described this condition arising in a femoral hernia, most of the cases reported as "Littre' hernias" have involved inguinal hernias. In 1980, Perlmarñ et al (4) described only the forty-fourth case of true Littre's hernia since the original account in 1700 . The inci 0 dence of complications of Meckel's diverticulum is saiç్ట 
to decrease with advancing years $(9,16)$. We believe this lady of 95 years is the most elderly patient recorded to present with a complication of a Meckel's diverticulum.

\section{Acknowledgements}

We would like to thank Mr D S MacPherson and $\mathrm{Mr} \mathrm{P}$ $S$ Veitch for their kind permission to report on their patients.

\section{REFERENCES}

1. MCDOWELl D E, Bush M. Fish bone perforation of Meckel's diverticulum simulating a leaking aortic aneurysm. South Med J 1982; 75(7): 891-2.

2. BROWN C K, OlShaKeR J S. Meckel's diverticulum. Am J Emerg Med 1988; 6(2): 157-64.

3. MeCKel J F. Handbuch der Pathologischen Anatomie: vol 1. Leipzig: CH Reclam, 1812.

4. Perlman J A. Hoover H C, Safer P K. Femoral hernia with strangulated Meckel;s diverticulum (Littre's hernia). Am J Surg 1980; 139: 286-9.

5. Gough D B, GoreY T F. Meckel's diverticulum. Surgery 1990; 80: 1913-5.

6. LUDTKE F E, MENDE V, KOHLER H, et al. Incidence and frequency or complications and management of Meckel's diverticulum. Surg Gynecol Obstet 1989; 169(6): 537-42.

7. SIMPSON R L: Ileocaecal intussusception of a previously recognised Meckel's diverticulum. Aust N Z J Surg 1985; 55(2): 09-11.
8. Garretson D C, Frederich M E. Meckel's diverticulum. Am Fam Physician 1990; 42(1): 115-9.

9. Leijonmarck C E, Bonman-Sandelin K, Frisel RAF L. Meckel's diverticulum in the adult. $\mathrm{Br} J$ Sir $g$ 1986; 73(2): 146-9.

10. MACKEY W C, DINEEN P. A fifty year experience with Meckel's diverticulum. Surg Gynecol Obstet 1 83 ; 156(1): 56-64.

11. PICKARD M A, Simpson C J. Meckel's diverticulain an adult surgical unit eleven years experience. $S \mathscr{E}$ ott Med J 1985; 30(3): 175-6.

12. BLANC H H. Contribution a la pathologie du di ticule de Meckel. These de Paris, 1899.

13. Skandalakis J E, Gray S W. Smooth musiele tumours of the alimentary tract. In Ariel IM, gd. Progress in Clinical Cancer. New York: Grune and Stratton, 1965; 692-708.

14. YEU-TSU N, LEE M. Leiomyoma of the gas t艹ّintestinal tract: general pattern of metastasis and recurrence. Cancer Treat Rev 1983; 10: 91-101.

15. RANCHOD M, KEMPSON R L. Smooth muscle tumöirs of the gastro-intestinal tract and retroperitoneum? A pathologic analysis of 100 cases. Canfer 1977; 39: 255-262.

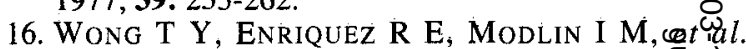
Recurrent hemorrhage from an invaginated Meokee's diverticulum in a 78-year old man. Am $J$ Gas 90 enterol 1990; 85(2): 195-8. 